PROFESIONAL HEALTH JOURNAL

Volume2, No. 2, Juni 2021 (Hal. 112-121)

https://www.ojsstikesbanyuwangi.com/index.php/PHJ

\title{
Faktor-Faktor yang Berhubungan dengan Persalinan Prematur
}

\author{
Violita Siska Mutiara ${ }^{\text {a }}$, Nuril Absaria ${ }^{\mathrm{a}}$, Ida Rahmawati ${ }^{\mathrm{b}}$, Putri Andini ${ }^{\mathrm{a}}$ \\ aProgram Studi Kebidanan STIKES Tri Mandiri Sakti, Bengkulu, Indonesia \\ bProgram Studi Keperawatan STIKES Tri Mandiri Sakti, Bengkulu, Indonesia \\ Email Korespondensi: idarahmawati1608@gmail.com
}

\begin{abstract}
Introduction: Premature is a labor before 37 weeks of gestation or is birth weight of an infant between 500-2499 grams. The impact of premature birth is that the premature infants will need intensive care to survive. This research aimed to study factors associated with preterm labor. Methode The research used Analytical Survey method with Case Control design. The population were all woman who gave birth in RSUD dr. M. Yunus Bengkulu in 2018, which were 603 deliveries. Samples taken were 88 mothers including 44 mothers with preterm labor who were selected by using Total Sampling and 44 mothers without preterm labor who were selected by using Systematic Random Sampling. The research used secondary data. The data were analyzed using univariate, bivariate and multivariate analysis with Chi Square $\left(\chi^{2}\right)$ and Contingency Coefficient $(C)$ tests. Result: The results obtained 44 women (50.0\%) with preterm labor, 44 women (50.0\%) with non-preterm labor, 61 women (69.3\%) aged 20-35 years, 52 women (59.1\%) with multiparous parity, 61 women (69.3\%) without premature rupture of membranes (PROM). The result of analysis showed there was correlation between age and preterm labor. The correlation is included in moderate category. There was correlation of parity with preterm labor, which is included in close category. Conclucion:There was also correlation of PROM with preterm labor, which is included in close category. It is expected that health workers can increase screening for the pregnant women who visit Midwifery Clinic to conduct early detection of pregnancy at risk so that it does not have any impact on preterm labor.
\end{abstract}

Keywords: PROM, Parity, Preterm Labor, Maternal Age

\begin{abstract}
ABSTRAK
Pendahuluan: Persalinan prematur adalah persalinan sebelum usia kehamilan 37 minggu atau berat badan lahir antara 500-2499 gram. Dampak kelahiran prematur kemungkinan bayi yang dilahirkan prematur akan membutuhkan perawatan intensif untuk bertahan hidup. Penelitian ini bertujuan untuk mempelajari faktor-faktor yang berhubungan dengan persalinan prematur di Ruang Mawar RSUD Dr. M. Yunus Bengkulu tahun 2018. Metode: Penelitian menggunakan metode Survey Analitik dengan rancangan Case Control. Populasi adalah semua ibu bersalin di RSUD dr. M. Yunus Bengkulu tahun 2018 sebanyak 603 persalinan. Sampel diambil sebanyak 88 ibu bersalin yang terdiri dari 44 ibu dengan
\end{abstract}


persalinan prematur diambil secara Total Sampling dan 44 ibu tidak persalinan prematur yang diambil secara Systematic Random Sampling. Data yang digunakan adalah data sekunder. Data dianalisis menggunakan analisis univariat, bivariate dan multivariate dengan uji Chi Square $\left(\chi^{2}\right)$ dan Contingency Coefficient $(C)$. Hasil: Hasil penelitian didapatkan dari 88 ibu terdapat $44(50,0 \%)$ ibu dengan persalinan prematur, $44(50,0 \%)$ ibu persalinan tidak prematur, $61(69,3 \%)$ ibu usia 20-35 tahun, $52(59,1 \%)$ ibu paritas multipara, $61(69,3 \%)$ ibu tidak KPD, ada hubungan usia dengan persalinan prematur dengan kategori hubungan sedang, ada hubungan paritas dengan persalinan prematur dengan kategori hubungan erat, ada hubungan KPD dengan persalinan prematur dengan kategori hubungan erat. Kesimpulan: Diharapkan tenaga kesehatan dapat meningkatkan skrining pada ibu hamil yang berkunjung ke Poli Kebidanan untuk melakukan deteksi dini kehamilan beresiko agar tidak berdampak pada persalinan prematur.

Kata Kunci: KPD, Paritas, Persalinan Prematur, Usia Ibu

\section{PENDAHULUAN}

Persalinan kurang bulan (prematur) adalah persalinan sebelum usia kehamilan 37 minggu atau bayi berat lahir dengan 500-2499 gram. Kejadian prematur masih tinggi dan merupakan penyebab utama kematian neonatus. Amerika Serikat mempunyai angka kejadian berkisar 8-10\% sementara Indonesia $16-18 \%$ dari semua kelahiran hidup. Ibu yang memiliki riwayat melahirkan bayi prematur berisiko 20-30\% beresiko kembali pada kehamilan berikutnya. Akan tetapi, 50\% ibu yang melahirkan prematur tidak mempunyai faktor resiko (Wahyuni \& Rohani, 2017). Faktor-faktor yang mempengaruhi persalinan premature menurut Rahmawati (2013) adalah jarak kehamilan, paritas, anemia. Dan anemia merupakan faktor yang paling dominan terhadap kejadian persalinan prematur. Sedangkan faktor usia ibu pada waktu kehamilan kurang dari 20 tahun dan lebih dari 35 tahun, tidak berpengaruh terhadap kejadian tersebut.

Dampak pada persalinan prematur adalah kemungkinan bayi yang dilahirkan akan mengalami gangguan beberapa fungsi organ tubuh sehingga membutuhkan perawatan intensif untuk bertahan hidup.
Kemampuan hidup bayi premature selain ditentukan oleh berat badan, juga ditentukan oleh usia gestasi. Selain masalah ketahanan hidup, masalah penting lain adalah kualitas hidup yang di capai oleh bayi prematur dan memiliki berat badan lahir rendah (Oktarina, 2016).

Berdasarkan data profil kesehatan Provinsi Bengkulu pada tahun 2014 terdapat jumlah kematian neonatal dan bayi sebesar 374 (Dinkes Provinsi Bengkulu, 2015). Survei awal dilakukan pada tanggal 18 Januari 2019 di RSUD dr. M. Yunus Bengkulu persalinan prematur mengalami peningkatan 3 tahun berturut-turut yaitu pada Tahun 2016 sebanyak 29 kasus dari 478 persalinan, Tahun 2017 menjadi 34 kasus dari 501 persalinan, dan tahun 2018 menjadi 44 kasus dari 603 persalinan, di mana sebanyak 22 ibu yang berusia $<20$ dan > 35 tahun, 30 ibu primipara dan Gerandemultipara dan 24 ibu mengalami KPD (Register Ruang Mawar Kebidanan RSUD Dr. M. Yunus Bengkulu, 2019)

Rumusan masalah dalam penelitian ini adalah faktor-faktor apa saja yang berhubungan dengan persalinan prematur di RSUD Dr. M. Yunus Kota Bengkulu Tahun 2018? Tujuan penelitian ini adalah 
untuk mempelajari faktor yang berhubungan dengan persalinan prematur di Ruang Mawar RSUD Dr. M. Yunus Bengkulu tahun 2018.

\section{METODE PENELITIAN}

Penelitian menggunakan metode Survey Analitik dengan rancangan Case Control. Populasi adalah semua ibu bersalin di RSUD dr. M. Yunus Bengkulu tahun 2018 sebanyak 603 persalinan. Sampel diambil sebanyak 88 ibu bersalin yang terdiri dari 44 ibu dengan persalinan prematur diambil secara Total Sampling dan $44 \mathrm{ibu}$ dengan persalinan aterm yang diambil secara Systematic Random
Sampling. Data yang digunakan adalah data sekunder. Data dianalisis menggunakan analisis univariat, bivariate dan multivariate dengan uji Chi Square $\left(\chi^{2}\right)$ dan Contingency Coefficient $(C)$.

\section{HASIL PENELITIAN}

\section{Analisis Univariat}

Analisis ini dilakukan untuk mendapatkan distribusi frekuensi usia, paritas dan KPD sebagai variabel independent dan persalinan prematur sebagai variabel dependent. Setelah penelitian dilaksanakan maka diperoleh data sebagai berikut:

Tabel 1 analisis univariat

\begin{tabular}{|c|c|c|c|}
\hline No & Univariat & Frekuensi & Persentase (\%) \\
\hline \multirow[t]{4}{*}{1.} & Usia & & \\
\hline & a. $<20$ th atau 35 th & 27 & 30,7 \\
\hline & b. 20-35 tahun & 61 & 69,3 \\
\hline & Total & 88 & 100 \\
\hline \multirow[t]{4}{*}{2.} & Paritas & & \\
\hline & a. Primi dan Grande Multipara & 36 & 40,9 \\
\hline & b. Multipara & 52 & 59,1 \\
\hline & Total & 88 & 100 \\
\hline \multirow[t]{4}{*}{3.} & Kejadian KPD & & \\
\hline & a. $\mathrm{Ya}$ & 27 & 30,7 \\
\hline & b. Tidak & 61 & 69,3 \\
\hline & Total & 88 & 100 \\
\hline \multirow[t]{3}{*}{4.} & Persalinan Prematur & 44 & 50 \\
\hline & $\begin{array}{ll}\text { a. } & \text { Ya } \\
\text { b. } & \text { Tidak }\end{array}$ & 44 & 50 \\
\hline & Total & 88 & 100 \\
\hline
\end{tabular}

Berdasarkan tabel 1. Didapatkan bahwa sebgian besar responden berusia 2035 tahun (69,3\%). Sebagian besar mempunyai riwayat paritas multipara sebanyak 52 orang $(59,1 \%)$. Dengan tidak mempunyai riwayat KPD 61 orang $(69,3 \%)$. Dan mempunyai riwayat persalinan premature sebanyak 44 orang (50\%).

\section{Analisis Bivariat}

Analisis bivariat dilakukan untuk mengetahui faktor-faktor yang berhubungan dengan kejadian. Persalinan prematur dan keeratannya. Berdasarkan 
hasil penelitian yang dilakukan, maka tabulasi silang antara variabel independent dan dependent dapat dilihat pada tabel di bawah ini:

Tabel 2 Tabulasi Silang faktor-faktor yang berhubungan dengan kejadian persalinan prematur

\begin{tabular}{|c|c|c|c|c|c|c|c|c|}
\hline \multirow{3}{*}{ Usia } & \multicolumn{4}{|c|}{ Persalinan prematur } & \multirow{3}{*}{-Total } & \multirow{3}{*}{$\chi^{2}$} & \multirow{3}{*}{$p$} & \multirow{3}{*}{$C$} \\
\hline & \multicolumn{2}{|c|}{ Ya } & \multicolumn{2}{|c|}{ Tidak } & & & & \\
\hline & $\mathrm{F}$ & $\%$ & $\mathrm{~F}$ & $\%$ & & & & \\
\hline$<20$ atau $>35 \mathrm{Th}$ & 22 & 81,5 & 5 & 18,5 & 27 & \multirow{2}{*}{13,678} & \multirow{2}{*}{0.000} & \multirow{2}{*}{0,546} \\
\hline $20-35 \mathrm{Th}$ & 22 & 36,1 & 39 & 63,9 & 61 & & & \\
\hline Total & 44 & 50,0 & 44 & 50,0 & 88 & & & \\
\hline \multirow{3}{*}{ Paritas } & \multicolumn{4}{|c|}{ Persalinan prematur } & & \multirow{3}{*}{$\chi^{2}$} & \multirow{3}{*}{$p$} & \multirow{3}{*}{$C$} \\
\hline & \multicolumn{2}{|c|}{ Ya } & \multicolumn{2}{|c|}{ Tidak } & \multirow{2}{*}{-Total } & & & \\
\hline & $\mathrm{F}$ & $\%$ & $\mathrm{~F}$ & $\%$ & & & & \\
\hline Primipara & $\operatorname{atau}_{30}$ & 83,3 & 6 & 16,7 & 36 & \multirow{2}{*}{24,868} & \multirow{2}{*}{0.000} & \multirow{2}{*}{0,685} \\
\hline $\begin{array}{l}\text { Urandemuitupara } \\
\text { Multipara }\end{array}$ & 14 & 26,9 & 38 & 73,1 & 52 & & & \\
\hline Total & 44 & 50,0 & 44 & 50,0 & 88 & & & \\
\hline \multirow{3}{*}{ KPD } & \multicolumn{4}{|c|}{ Persalinan prematur } & & \multirow{3}{*}{$\chi^{2}$} & \multirow{3}{*}{$p$} & \multirow{3}{*}{$C$} \\
\hline & \multicolumn{2}{|c|}{ Ya } & \multicolumn{2}{|c|}{ Tidak } & Totol & & & \\
\hline & $\bar{F}$ & $\%$ & $\mathrm{~F}$ & $\%$ & rotal & & & \\
\hline KPD & 24 & 88,9 & 3 & 11,1 & 27 & \multirow{2}{*}{21,372} & \multirow{2}{*}{0.000} & \multirow{2}{*}{0,65} \\
\hline Tidak KPD & 20 & 32,8 & 41 & 67,2 & 61 & & & \\
\hline Total & 44 & 50,0 & 44 & 50,0 & 88 & & & \\
\hline
\end{tabular}

Berdasarkan Tabel 2 di atas tampak tabulasi silang antara usia dengan persalinan prematur, ternyata Dari 27 orang usia $<20$ th Atau $>35$ tahun terdapat 22 orang prematur dan 5 orang tidak prematur, dan dari 61 orang usia 20-35 tahun terdapat 22 orang prematur dan 39 orang tidak prematur. Hasil Chi-Square (continuity

Tabulasi silang antara paritas dengan persalinan prematur, ternyata Dari 36 orang primipara atau grandemultipara terdapat 30 orang prematur dan 6 orang tidak prematur, dan dari 52 orang multipara terdapat 14 orang prematur dan 38 orang tidak prematur. Hasil Chi-Square (continuity correction) didapat nilai $\chi^{2}=24,868$

Tabulasi silang antara KPD dengan persalinan prematur. Dari 27 orang KPD correction) didapat nilai $\chi^{2}=13,678$ dengan $\mathrm{p}=$ value $=0,000<0,05 \quad$ berarti signifikan, maka Ho ditolak dan $\mathrm{Ha}$ diterima. Jadi usia berhubungan signifikan dengan kejadian partus prematur. Hasil uji Contingency Coefficient didapat nilai $\mathrm{C}=0,386$ dengan kategori hubungan sedang.

dengan $\mathrm{p}=$ value $=0,000<0,05 \quad$ berarti signifkan, maka Ho ditolak dan $\mathrm{Ha}$ diterima, jadi paritas berhubungan signifikan dengan kejadian partus prematur. Hasil uji Contingency Coefficient didapat nilai $\mathrm{C}=0,485$ dengan kategori hubunangan erat.

terdapat 24 orang prematur dan 3 orang tidak prematur, dan dari 61 orang tidak 
KPD terdapat 20 orang prematur dan 41 orang tidak prematur. Hasil Chi-Square (continuity correction) didapat nilai $\chi^{2}=$ 21,372 dengan $\mathrm{p}=$ value $=0,000<0,05$ berarti signifkan, maka Ho ditolak dan $\mathrm{Ha}$

Analisis multivariat dilakukan untuk melihat variabel bebas yang paling berhubungan dengan variabel terkait. Hasil penelitian menunjukkan seluruh variabel diterima, jadi KPD berhubungan signifikan dengan kejadian partus prematur. Hasil uji Contingency Coefficient didapat nilai $\mathrm{C}=0,460$ dengan kategori hubunangan erat.

\section{Analisis Multivariat}

memiliki nilai sig. $(p$-value $)=0,000$, berarti variabel usia, paritas dan KPD sig.( $p$-value) $<0,25$ memenuhi syarat untuk dapat dilanjutkan ke analisis multivariat.

Tabel 3 Pemodelan Multivariat

\begin{tabular}{llllllll}
\hline Variabel & \multirow{2}{*}{$\mathrm{B}$} & $\mathrm{SE}$ & Beta & $P$ & $\operatorname{Exp}(B)$ & $\begin{array}{l}\text { 95\% } \\
\text { EXP(B) }\end{array}$ & C.I.for \\
\hline (Constant) & -4.949 & 1.025 & 23.323 & & & & \\
Usia & 2.265 & 0.730 & 9.619 & 0.002 & 9.634 & 2.302 & -40.317 \\
Paritas & 2.712 & 0.682 & 15.832 & 0.000 & 15.063 & 3.960 & -57.298 \\
KPD & 2.366 & 0.778 & 9.240 & 0.002 & 10.658 & 2.318 & -49.010 \\
\hline
\end{tabular}

Berdasarkan Tabel 3, semua variabel independen nilai p value uji wald (Sig) $<0,05$, artinya masing-masing variabel mempunyai pengaruh parsial yang signifikan terhadap Prematur di dalam model. Usia mempunyai nilai Sig Wald 0,002 < 0,05 berarti usia memberikan pengaruh parsial yang signifikan terhadap kejadian prematur. Paritas mempunyai nilai Sig Wald $0,000<0,05$ berarti paritas memberikan pengaruh parsial yang signifikan terhadap kejadian prematur. KPD mempunyai nilai sig. Wald $0,002<0,05$ berarti variabel KPD memberikan pengaruh parsial terhadap prematur.

Berdasarkan permodelan multivatiat tersebut paritas merupakan variabel yang paling berpengaruh dengan kejadian partus prematur dengan $O R=15,063$, artinya pasien paritas primipara atau grandemultipara, beresiko prematur sebesar 15.063 kali lipat jika di bandingkan dengan multipara.

\section{PEMBAHASAN}

Hasil penelitian dari 88 orang terdapat 44 orang persalinan prematur karena 5 orang usia $<20$ tahun, paritas primipara dengan KPD, 18 orang anemia, 7 orang PEB, 1 orang PEB dengan anemia, 2 orang eklampsia, 4 orang plasenta previa, 3 orang pendidikan dasar, 2 orang mola hidatidosa dan 1 orang grandemultipara dengan KPD dan 1 orang usia 19 tahun paritas primipara, Sedangkan 44 orang tidak persalinan prematur karena ibu tidak mengalami komplikasi yang dapat menyebabkan partus prematur.

Bayi dikatakan prematur jika usia kandungan belum mencapai atau baru memasuki minggu ke 37 sehingga cenderung mengalami beberapa masalah dibanding bayi normal. Beberapa masalah yang terjadi adalah organ belum berfungsi normal sehingga dapat menyebabkan gangguan seperti gangguan 
pernapasan, berat badan kurang, dan perlu mendapatkan perawatan khusus (Subekti, 2005). Hasil penelitian dari 88 orang terdapat 27 orang usia $<20$ atau $>35$ tahun yaitu 21 orang usia $>35$ tahun dan 6 orang usia $<20$ tahun menunjukkan bahwa ibu dengan usia beresiko saat melakukan kehamilan dan persalinan dan 61 orang usia 20-35 tahun menunjukkan bahwa ibu bersalin dengan usia reproduksi yang ideal saat melakukan kehamilan dan persalinan.

Usia kehamilan kurang dari 20 atau atau lebih dari 35 tahun sangat beresiko komplikasi kehamilan dan persalinan. Usia 20-35 merupakan usia yang tepat untuk reproduksi, karena fungsi organ masih baik untuk terjadi kehamilan (Purwanti \& Trisnawati, 2016). Hasil penelitian dari 88 orang terdapat 36 orang paritas primipara atau grandemultipara yaitu 11 orang dengan paritas grandemultipara terdiri dari 8 orang memiliki anak lima orang dan 3 orang memiliki anak 6 orang dan 25 orang dengan paritas primipara yaitu telah memiliki akan sebanyak 1 orang dan 52 orang paritas multipara menunjukkan bahwa ibu bersalin dengan paritas yang ideal karena memiliki anak 2-4 orang.

Paritas seorang perempuan dapat dibedakan menjadi primipara telah pernah melahirkan sebanyak satu kali, multipara telah melahirkan dua hingga empat kali dan grandemultipara telah melahirkan 5 orang anak atau lebih (Nurjayanti, 2018). Hasil penelitian dari 88 orang terdapat 27 orang mengalami ketuban pecah dini terjadi saat akan melakukan proses persalinan diantaranya karena usia dan paritas beresiko, kelainan letak dan preeklampsia, Sedangkan 61 orang tidak ketuban pecah dini usia dan paritas tidak beresiko dan tidak mengalami komplikasi seperti preeklampsia, anemia dan mola hidatidosa.

Prematur juga dapat disebabkan oleh ketuban pecah dini (KPD). Penelitian (Arsiana, Mariati, \& Yuniarti, 2012) menunjukan bahwa KPD dapat dipengaruhi Disproposi Kepala Panggul (DKP), paritas primipara dan grandemultipara, premature dan post matur.

Hasil penelitian dari 27 orang usia $<20$ atau $>35$ tahun terdapat 22 orang persalinan prematur 6 orang usia $<20$ tahun menunjukkan bahwa organ reproduksi ibu belum sempurna untuk melakukan proses reproduksi dan 16 orang usia > 35 tahun menunjukkan telah terjadi penurunan fungsi reproduksi akibat proses penuaan sehingga usia $<20$ atau $>35$ tahun jika melakukan kehamilan beresiko melahirkan secara prematurus.

Hasil penelitian dari 27 orang usia $<20$ atau > 35 tahun terdapat 5 orang tidak persalinan prematur karena paritas yang ideal yaitu multipara, karena pendidikan tinggi (S1) dan menengah (SMA) sehingga mudah menerima dan mencari informasi tentang kesehatan, dan seluruh ibu tidak mengalalami komplikasi kehamilan seperti preeklampsia, anemia, plasenta previa, eklampsia dan komplikasi lainnya sehingga kondisi usia beresiko yang dimiliki ibu tidak berdampak pada terjadinya persalinan prematur.

Hasil penelitian dari 61 orang usia 20-35 tahun terdapat 22 orang persalinan prematur yaitu 12 orang mengalami anemia, 1 orang mengalami eklampsia, 2 orang mengalami PEB, 2 orang melngalami plasenta previa, 3 orang pendidikan dasar, 1 orang mengalami mola hidatidosa dan 1 orang dengan paritas grandemultipara dan KPD sehingga kondisi tersebut berdampak pada terjadinya persalinan prematurus. 
Hasil penelitian dari 61 orang usia 20-35 tahun terdapat dan 39 orang tidak persalinan prematur karena pada usia 20-35 tahun ibu berada pada usia reproduksi yang ideal dan sudah siap untuk melakukan proses reproduksi sehingga memiliki resiko komplikasi kehamilan dan persalinan yang kecil dan tidak terjadi persalinan prematur.

Hasil uji statistik Chi-Square (Continuity Correction) terdapat hubungan yang signifikan antara usia dengan kejadian persalinan prematur di RSUD dr. M. Yunus Bengkulu. Hasil penelitian ini menunjukkan bahwa usia ibu pada saat melakukan proses kehamilan dapat mengakibatkan terjadinya persalinan prematur.

Hasil penelitian ini sejalan dengan hasil penelitian Utami (2014) tentang hubungan antara usia dan paritas ibu bersalin dengan kejadian persalinan prererm di Kabupaten Bantul, menunjukkan bahwa sebagian besar responden mempunyai usia tidak beresiko dan mengalami persalinan cukup bulan, yaitu 34 responden $(89,5 \%)$. Responden paling sedikit adalah yang mempunyai umur beresiko dan mengalami persalinan cukup bulan, yaitu 4 responden $(10,5 \%)$. Ada hubungan usia dengan kejadian persalinan prererm.

Hasil uji Contingency Coefficient didapat kategori hubungan sedang antara usia dengan persalinan prematur. Kategori hubungan sedang menunjukkan bahwa ada faktor lain yang dapat mengakibatkan terjadinya persalinan prematur selain dari usia ibu diantaranya adalah preeklampsia, kekurangan gizi, anemia dan sosial ekonomi yang rendah.

Hasil penelitian dari 36 orang paritas primipara atau grandemultipara terdapat 30 orang persalinan prematur yaitu 20 orang karena memiliki anak satu menunjukkan baru pertama kali melakukan poses kehamilan sehingga pengetahuan dan pengalaman ibu masih kurang, sedangkan 10 orang memiliki anak lebih dari empat orang menunjukkan telah mengalami penurunan fungsi reproduksi akibat terlalu sering hamil dan melahirkan sehingga pada paritas beresiko berdampak pada terjadinya persalinan prematur.

Hasil penelitian dari 36 orang paritas primipara atau grandemultipara terdapat dan 6 orang usia ideal sehingga reproduksi sudah siap untuk proses kehamilan dengan pendidikan SMA, karena pendidikan s1 sehingga mudah mencari dan menerima informasi kesehatan, usia ideal dengan pendidikan SMA dan seluruh ibu tidak mengalami komplikasi lain sehingga paritas beresiko yand dimiliki tidak berdampak pada kondisi persalinan prematur.

Hasil penelitian dari 52 orang paritas multipara terdapat 14 orang persalinan prematur yaitu karena 2 orang dengan kehamilan mola hidatidosa, 4 orang mengalami anemia, 3 orang mengalami PEB, 2 orang mengalami eklampsia, 1 orang pendidikan dasar mengalami KPD, dan 2 orang plasenta previa ibu serta beberapa ibu dengan usia beresiko dan mengalami komplikasi KPD sehingga kondisi tersebut berdampak pada terjadinya persalinan prematur.

Hasil penelitian dari 52 orang paritas multipara terdapat dan 38 orang tidak persalinan prematur karena pada ibu dengan paritas multipara anak yang dilahirkan ibu belum terlalu banyak, kondisi kesehatan reproduksi ibu masih dalam keadaan prima belum mengalami penurunan fungsi akibat terlalu sering melahirkan sehingga ibu tidak dengan paritas multipara tidak mengalami persalinan prematur. 
Hasil uji statistik Chi-Square (Continuity Correction) terdapat hubungan yang signifikan antara paritas dengan kejadian persalinan prematur di RSUD dr. M. Yunus Bengkulu. Hasil penelitian ini menunjukkan bahwa jumlah anak yang dimiliki ibu pada saat melakukan proses kehamlan dapat menyebabkan terjadinya persalinan prematur.

Studi yang dilakukan Wahyuni \& Rohani (2017) menemukan adanya hubungan yang kuat antara peluang persalinan prematur dan pola fertilitas. Secara umum, peluang persalinan prematur adalah lebih tinggi pada anak yang dilahirkan oleh ibu yang berumur terlalu tua atau terlalu muda, dilahirkan setelah jarak kelahiran yang pendek, atau dilahirkan oleh ibu dengan paritas yang tinggi.

Hasil uji Contingency Coefficient didapat kategori hubungan erat antara paritas dengan persalinan prematur. Kategori hubungan erat menunjukkan bahwa paritas berhubungan secara dominan pada terjadinya persalinan prematur artinya ibu dengan paritas beresiko bisa dipastikan akan mengalami kelahiran prematur.

Hasil penelitian dari 27 orang KPD terdapat 24 orang persalinan prematur karena pada ibu yang mengalami ketuban pecah dini sangat beresiko pada persalinan yang dilakukan tidak cukup bulan sehingga harus dilakukan pertolongan persalinan secara segera untuk menyelamatkan ibu dan bayinya, jika air ketuban sudah habis, maka persalinan normal sudah tidak bisa ditangani.

Hasil penelitian dari 27 orang KPD terdapat 3 orang tidak persalinan prematur dengan paritas multipara, pendidikan S1 dan SMA serta seluruh ibu tidak mengalami komplikasi sehingga KPD yang terjadi tidakberdampak pada persalinan prematur.
Hasil penelitian dari 61 orang tidak KPD terdapat 20 orang persalinan prematur yaitu 8 orang mengalami anemia, 6 orang mengalami PEB, 2 orang mengalami mola hidatidosa, 1 orang mengalami eklampsia, 2 orang mengalami plasenta previa dan1 orang usia beresiko dengan paritas primipara sehingga kondisi-kondisi tersebut berdampak pada terjadinya persalinan prematur.

Hasil penelitian dari 61 orang tidak KPD terdapat 41 orang tidak persalinan prematur karena pada ibu yang tidak mengalami KPD tidak terjadi penurunan jumlah cairan ketuban sehingga persalinan dapat dilakukan sesuai waktu yang seharusnya dan tidak berakibat pada persalinan prematurus.

Hasil uji statistik Chi-Square (Continuity Correction) terdapat hubungan yang signifikan antara KPD dengan kejadian persalinan prematur. KPD dibagi menjadi dua kategori yaitu KPD preterm adalah KPD sebelum usia kehamilan 37 minggu. KPD yang memanjang adalah KPD yang terjadi lebih dari 12 jam sebelum waktunya melahirkan (Riyanti, 2018). KPD merupakan komplikasi yang berhubungan dengan kehamilan kurang bulan, dan mempunyai kontribusi yang besar pada angka kematian perinatal pada bayi yang kurang bulan. Pengelolaan KPD pada kehamilan kurang bualan dari 34 minggu sangat komplek, bertujuan untuk menghilangkan kemungkinan terjadinya prematuritas dan RDS.

Hasil uji Contingency Coefficient didapat kategori hubungan erat. Kategori hubungan erat menunjukkan bahwa faktor ketuban pecah dini dominan menyebakan persalinan prematur.

Hasil analisis multivariat menunjukkan bahwa semua variabel independen (usia, paritas dan KPD) masing-masing mempunyai 
pengaruh parsial yang signifikan terhadap Prematur di dalam model. Hasil ini sejalan dengan pendapat Purnamasasri (2017) bahwa faktor-faktor yang mempengaruhi persalinan prematur adalah faktor usia ibu pada waktu kehamilan kurang dari 20 tahun dan lebih dari 35 tahun, suku bangsa dan kondisi sosial ekonomi rendah, berat badan ibu sebelum kehamilan dan sewaktu kehamilan, jarak kelahiran sebelumnya terlalu dekat, ibu hamil yang bekerja terlalu berat, paritas dan ketuban pecah dini.

Berdasarkan analisis multivatiat paritas merupakan variabel yang paling berpengaruh dengan kejadian partus prematur karena pasien yang paritas primipara atau grandemultipara beresiko terjadinya prematur sebesar 15.063 kali lipat jika di bandingkan dengan pasien yang paritas multipara. Hasil penelitian ini menunjukkan bahwa ibu yang memiliki anak 1 atau $>4$ orang lebih beresiko mengalami partus prematur dibandingkan dengan ibu bersalin yang memiliki anak 2-4 orang.

\section{KESIMPULAN}

Hasil penelitian didapatkan dari 88 ibu terdapat $44(50,0 \%)$ ibu dengan persalinan prematur, $44(50,0 \%)$ ibu persalinan tidak prematur, $61(69,3 \%)$ ibu usia 20-35 tahun, $52(59,1 \%)$ ibu paritas multipara, 61 $(69,3 \%)$ ibu tidak KPD, ada hubungan usia dengan persalinan prematur dengan kategori hubungan sedang, ada hubungan paritas dengan persalinan prematur dengan kategori hubungan erat, ada hubungan KPD dengan persalinan prematur dengan kategori hubungan erat.

\section{SARAN}

Paritas dan KPD sangat erat kaitannya dengan kejadian persalinan premtur, diharapkan untuk petugas kesehatan khususnya perawat maupun bidan agar dapat memberikan pendidikan kesehatan mengenai pentingnya mengatur paritas dan mampu mendeteksi dini adanya KPD pada ibu hamil agar tidak berdampak pada keadaan partus premature

\section{DAFTAR PUSTAKA}

Arsiana, D., Mariati, \& Yuniarti. (2012). Hubungan DKP dengan Kejadian Ketuban Pecah Dini di RSUD Dr. M. Yunus Bengkulu. Jurnal Media Kesehatan, 5(2), 101-205.

Dinkes Provinsi Bengkulu. (2015). Profil Dinas Kesehatan Provinsi Bengkulu. Dinas Kesehatan Provinsi Bengkulu.

Nurjayanti, P. D. (2018). Hubungan Paritas dan Umur Kehamilan dengan Kejadian Asfiksia pada Bayi Baru Lahir di RSUD Wonosari tahun 2016. Yogyakarta: Skripsi, Politeknik Kesehatan Kementerian Kesehatan Yogyakarta.

Oktarina, M. (2016). Buku Ajaran Asuhan Kebidanan Persalinan Dan Bayi Baru Lahir. Yogyakarta: Deepublish.

Purnamasasri, N. I. (2017). Faktor risiko kejadian persalinan prematur di rsup dr. wahidin sudirohusodo kota makassar provinsi sulawesi selatan. Makassar: Skripsi. Departemen Biostatistik Fakultas Kesehatan Masyaraka Universitas Hasanuddin Makssar.

Purwanti, S., \& Trisnawati, Y. (2016). Pengaruh Umur dan Jarak Kehamilan Terhadap Kejadian Perdarahan Karena Atonia Uteri. Jurnal Publikasi Kebidanan Akbid YLPP Purwokerto, 
PROFESIONAL HEALTH JOURNAL

Volume2, No. 2, Juni 2021 (Hal. 112-121)

https://www.ojsstikesbanyuwangi.com/index.php/PHJ

$5(3), 12-19$.

Rahmawati, D. (2013). Faktor-faktor yang mempengaruhi terjadinya persalinan preterm di RSUD dr. moewardi surakarta. Fakultas Ilmu Kesehatan Universitas Muhammadiyah Surakarta. Surakarta: Skripsi. Jurusan Keperawatan Fakultas Ilmu Kesehatan Universitas Muhammdiyah Surakarta. Retrieved from http://eprints.ums.ac.id/24128/10/NASK AH_PUBLIKASI.pdf

Riyanti, L. (2018). Determinan Kejadian Ketuban Pecah Dini (KPD) di Ruang Cempaka RSUD Dr. Doris Sylvanus Palangkaraya. Jurnal Surya Medika, 3(2), 95-105.

Subekti, N. B. (2005). Buku Saku Manajemen Masalah Bayi Baru Lahir : Panduan untuk Dokter, Perawat \& Bidan. (P. E. Karyuni \& E. Miliya, Eds.). Jakarta: EGC.

Utami, A. D. (2014). Hubungan antara usia dan paritas ibu bersalin dengan kejadian persalinan preterm di kabupaten bantul. STIKes 'Aisyiyah Yogyakarta. Yogyakarta: Skripsi. Program Studi Bidan Pendidik Jenjang DIV STIKES 'Aisyiyah Yogyakarta.

Wahyuni, R., \& Rohani, S. (2017). FaktorFaktor yang Mempengaruhi Persalinan Preterm. Jurnal Aisyah : Jurnal Ilmu Kesehatan, 2(1), 61-68. 